\title{
Temperature Evolution in Poplar (Populus nigra) Tension Wood and Normal Wood during a Conventional Drying Process
}

\author{
Asghar TARMIAN, Amir SEPEHR, MahdiSHAHVERDI \\ University of Tehran, Faculty of Natural Resources, Department of Wood and Paper Science and Technology, \\ Karaj,Iran;tarmian@ut.ac.ir,sepehr@nrf.ut.ac.ir,m_shahverdi@yahoo.com
}

\begin{abstract}
In this paper, temperature evolution through tension wood and normal wood in poplar (Populus nigra) under a convective drying condition was investigated. Flat-sawn boards with green dimensions $80 \times 40 \times 25 \mathrm{~mm}$ were dried at constant dry-bulb temperature of $60^{\circ} \mathrm{C}$ and relative humidity $(\mathrm{RH})$ of $50 \%$ to a final moisture content of about $8 \%$. They were coated on four surfaces using aluminum foil bonded with polyurethane (PU) glue to confine moisture movement along the board thickness. The measurement of board temperature was carried out at 2.5, 5, 7.5, 10 and $12.5 \mathrm{~mm}$ along the board thickness every 20 minutes by means of $1 \mathrm{~mm}$-thermocouples. The pattern of temperature profile was observed to be almost similar for both tension wood and normal wood. However, a slightly steeper temperature gradient occurred in the normal wood compared to the tension wood. In both types of woods, the surface temperature rose progressively from the initial value to the dry-bulb temperature but the core temperature remained at an almost constant value as the wet-bulb temperature even at the end of drying.
\end{abstract}

Keywords: drying, temperature evolution, tension wood, normal wood

\section{Introduction}

Heat transfer in wood is an important topic in drying technology. Wood as a typical orthotropic porous medium with a highly varied anatomical structure has complex drying behavior. Drying of wood is a complicated process involving simultaneous, coupled heat and mass transfer phenomena occurring inside the wood being dried. These phenomena are so sophisticated and structure dependent (Siau, 1984). Consequently, any irregularities, such as reaction wood, which negatively influences xylem water transport efficiency, may affect the transport processes on wood drying. The knowledge of temperature distributions within the wood during the drying process and understanding the fundamental mechanisms are essential for drying design, quality control, and energy savings. In addition, by measuring of temperature profile within wood, it is possible to predict the moisture flux rate (Wiberg and Moren, 1999). Many authors indicate that the temperature gradient should be considered as a driving force for moisture diffusion in wood in addition to other main driving forces, such as moisture concentration (Li et al., 2005; Pang, 1997; Tarmian et al., 2008). For mentioned reasons, temperature evolution in wood during drying has been extensively investigated (Cai, 2001; Li et al., 2005; Zielonka and Gierlik, 1999), and many mathematical models have been also developed to predict the wood temperature profile (Dedic et al., 2003; Zielonka and Gierlik, 1999).

The temperature evolution in wood during drying is related to many factors and the wood structure can influence this phenomenon. Keey et al. (2000) reported significant difference in temperature profile of sapwood and heartwood. Direction dependent of temperature evolution in wood on drying is also claimed by many researchers ( $\mathrm{Li}$ an 1994; Mouchot et al., 2006; Siau, 1984). A little information can be found in literature regarding transport processes in reaction woods (Davis et al., 2002; Tarmian and Perré, 2009; Tarmian et al., 2009; Williams, 1971). In the mentioned studies, the negative impact of reaction wood on the drying rate and permeability has been reported. Despite a number of studies focused on the temperature evolution in normal wood, there is a lack of information concerning the temperature evolution behavior of reaction wood. The present study attempts to characterize the temperature evolution in the tension wood of poplar $(P$. nigra) as compared with the corresponding normal wood.

\section{Materials and methods}

\section{Materials}

Tension wood and normal wood of poplar (Populus nigra) were selected for the study. Tension wood was macroscopically recognized by the shiny appearance and a specific coloring technique using a chemical reagent called Herzberg to precisely sample cut. In addition, the accuracy of sampling was proved by the presence of G-layer in the tension wood specimens. Flat-sawn boards with green dimensions $80 \times 40 \times 25 \mathrm{~mm}$ were cut. The samples were then wrapped immediately in plastic and stored in a cold room at approximately $4-5^{\circ} \mathrm{C}$ until required. 


\section{Drying method}

A conventional drying method at constant dry-bulb temperature of $60^{\circ} \mathrm{C}$ and relative humidity $(\mathrm{RH})$ of $50 \%$ was applied to dry all specimens in a small laboratory kiln. The boards were coated on four surfaces using aluminum foil bonded with polyurethane (PU) glue to confine moisture movement along the board thickness. The specimens were dried to a final moisture content of about $8 \%$ without any equalizing or conditioning treatment.

\section{Temperature evolution}

The PU-coated boards with two surfaces left uncoated were thermally insulated by $50 \mathrm{~mm}$-thick Styrofoam so that the temperature evolved through the board thickness. The measurement of board temperature was carried out at 2.5, $5,7.5,10$, and $12.5 \mathrm{~mm}$ along the board thickness every 20 minutes during the whole drying process. The temperature measurement was carried out using $1 \mathrm{~mm}$-thermocouples inserted in the holes previously made within the boards.

\section{Results and discussion}

\section{Temperature evolution}

The pattern of temperature evolution was observed to be almost identical for poplar tension wood and normal wood (Fig. 1). The surface temperature of both types of woods rose progressively from the initial value to the dry-bulb temperature but temperature below the surface showed a temperature value between the wet- and dry-bulb temperatures for a period of time. A similar temperature evolution for a convective drying process was reported by Keey et al. (2000) and Keey and Nijdam (2002). In a previous work on temperature evolution in the compression and opposite wood of spruce (P. abies) (Tarmian, 2008), the curve of temperature rise within opposite wood at
MC above FSP showed a constant temperature between the initial and dry-bulb temperatures for a period of time. In contrast, the compression wood temperature rose progressively to the dry-bulb temperature without a constant temperature (Fig. 2).

An almost similar rate of temperature evolution was observed for tension wood and normal wood (Tab. 1). However, a rapid rise in the temperature of both tension wood and normal wood was observed at the beginning of drying. This is a usual behavior in wood drying; in green condition at MC>FSP, the temperature of wood increases as heating up progresses until it reaches the wet bulb temperature within a short time. In contrast to the present study, Tarmian (2008) observed that compression wood had faster temperature evolution than the opposite wood during a conventional drying method.

\section{Temperature gradient}

The tension wood and normal wood exhibited a similar temperature gradient along the board thickness (Fig. 3 ). However, the temperature gradient between the surface and inner part of boards was slightly sharper in the case of normal wood. The core temperature of the boards remained at an almost constant value as the wet-bulb temperature for both tension wood and normal wood. This is a usual temperature gradient developed during a typical convective wood drying process; i.e., the temperature in the core is lower than one in the surface layer. However, unusual behavior may be occurred even in a conventional drying process (Remond et al., 2005; Tarmian, 2008). Sometimes, as soon as the drying starts, the core temperature increases above wet bulb temperature and approaches the dry-bulb temperature of the surrounding air. In this condition, the core temperature is greater than the surface temperature for a period of time and no constant drying
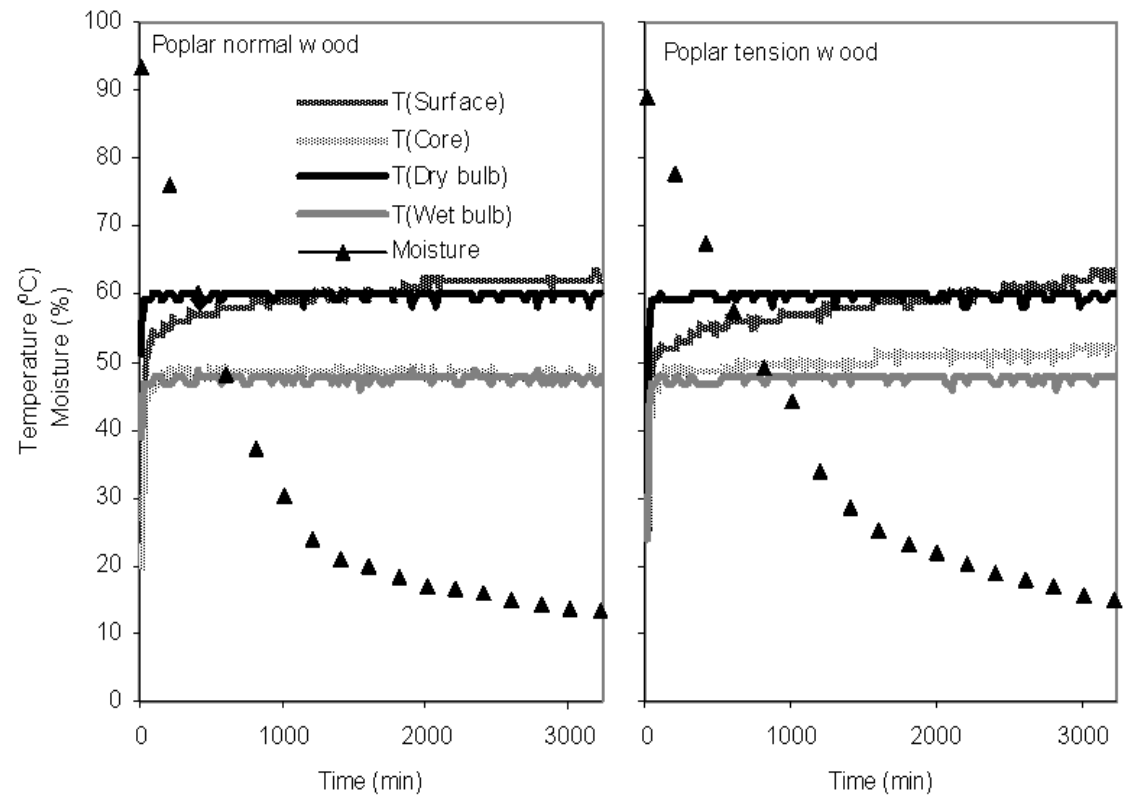

Fig. 1. Temperature evolution in poplar tension wood and normal wood during drying 

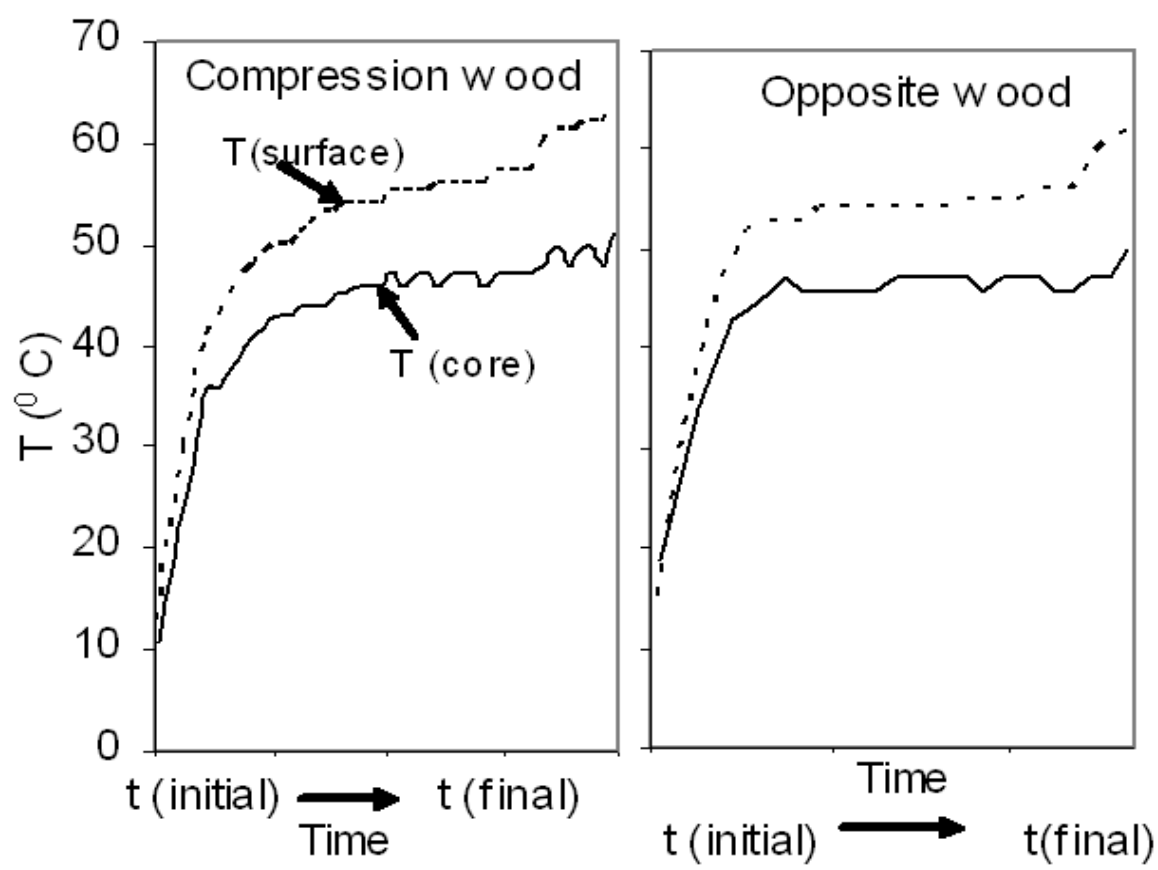

Fig. 2. Temperature evolution in compression and opposite wood of spruce ( $P$. abies) during a convective drying process at dry-bulb temperature of $60^{\circ} \mathrm{C}$ and relative humidity $(\mathrm{RH})$ of 50\% (after Tarmian, 2008)

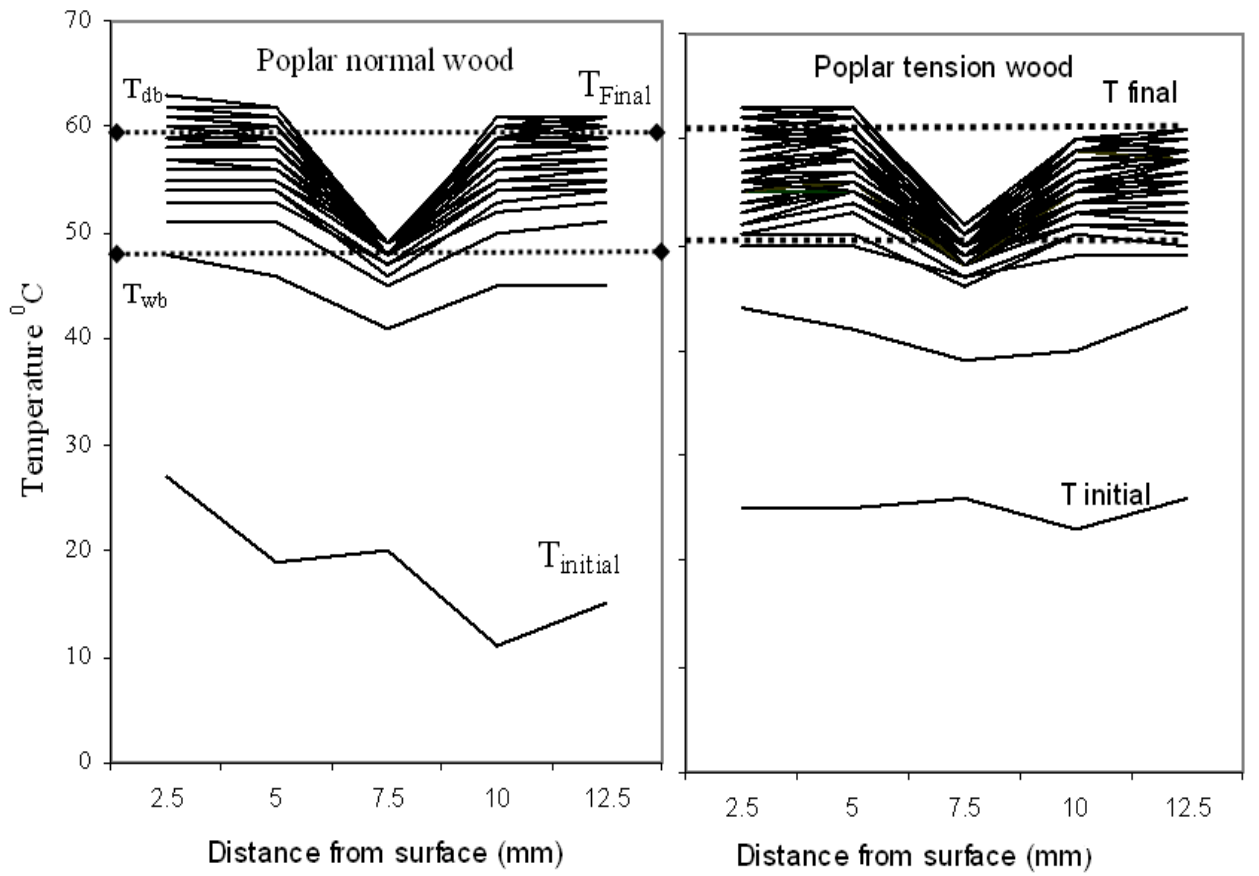

Fig. 3. The development of temperature gradient in poplar tension wood and normal wood during drying

rate period occurs. This phenomenon may occur during drying of impermeable thick boards at the domain of free water. This can be explained by the dry shell formation near the surface in the capillary regime of drying (Remond et al., 2005).

Similar to what was observed here for poplar tension wood and normal wood, Tarmian (2008) found an identi- cal pattern of temperature profile for spruce compression wood and normal wood (Fig. 4). The author also observed slightly steeper temperature gradient in the normal wood and furthermore, it took a slightly shorter time for the temperature gradient within the compression wood to be almost uniform. 

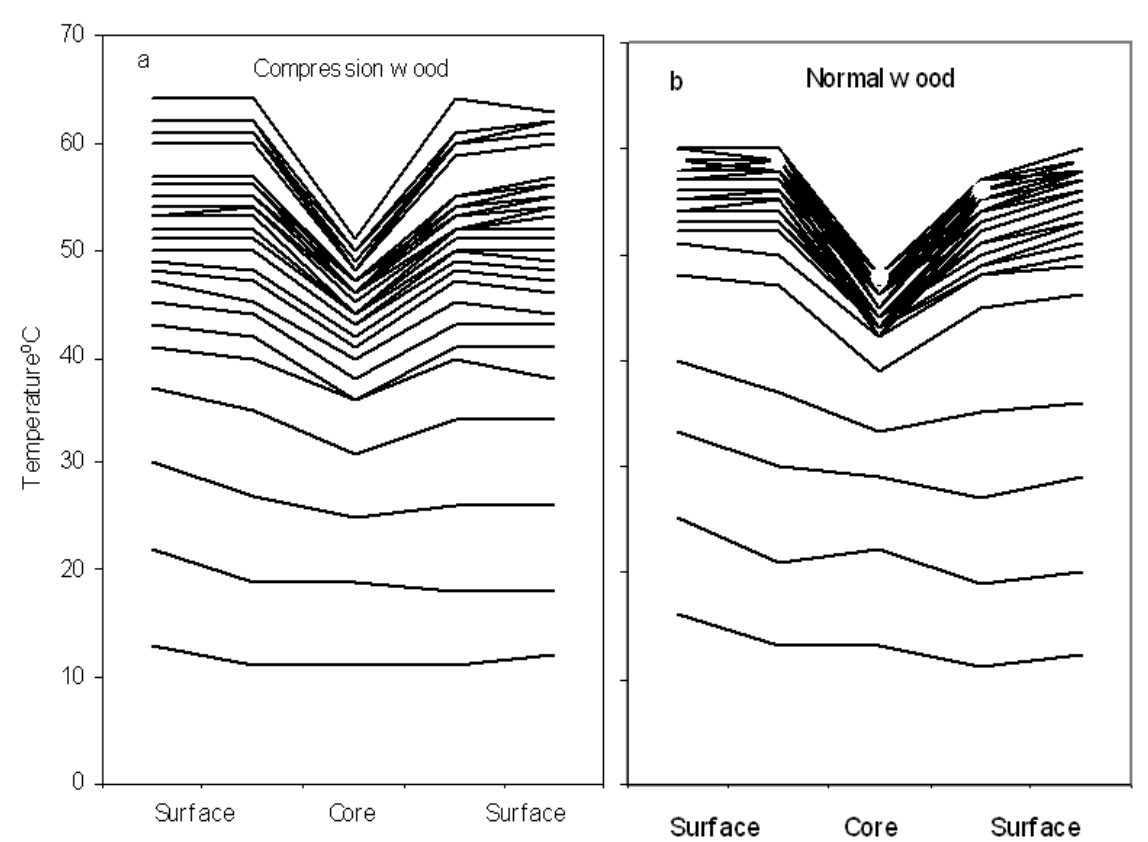

Fig. 4. The evolution of temperature profile along the flat-sawn board thickness in compression and normal wood of spruce (P. abies) (After Tarmian, 2008)

Tab. 1. The rate of temperature evolution in poplar tension wood and normal wood at the early stages of drying

\begin{tabular}{ccccccc}
\hline Wood type & $\begin{array}{c}\text { Time } \\
(\mathrm{min})\end{array}$ & \multicolumn{5}{c}{$\begin{array}{c}\text { Distance from surface } \\
(\mathrm{mm})\end{array}$} \\
\hline \multirow{5}{*}{ Tension wood } & & 2.5 & 5 & 7.5 & 10 & 12.5 \\
\cline { 2 - 6 } & 20 & 57 & 51 & 39 & 51 & 54 \\
\cline { 2 - 6 } & 40 & 18 & 24 & 24 & 27 & 15 \\
& 60 & 3 & 3 & -3 & 6 & 3 \\
\hline & 80 & 0 & 6 & 3 & 0 & 0 \\
\hline \multirow{5}{*}{ Temperature evolution rate $\left({ }^{\circ} \mathrm{C} / \mathrm{s}\right)$} \\
\hline
\end{tabular}

\section{Conclusions}

Tension wood is an abnormal woody tissue that typically develops in fast-growing trees on the upper side of leaning trees or branches but sometimes in other parts of the vertical tree trunk in response to various growth stresses. Poplar trees usually suffer from tension wood formation. Thus, the present study aimed to characterize the heat transfer features of poplar tension wood (a type of reaction wood) during a convective air drying process in comparison with the corresponding opposite wood. Results revealed a similar temperature evolution behavior for the tension wood and normal wood but slightly steeper temperature gradient in the normal wood. The result of this study is similar to what was observed for spruce compression and opposite wood by Tarmian (2008). However, more striking difference occurred in the temperature evolution behavior of the compression wood and normal wood in Picea abies. Similarly, Tarmian et al. (2009) and Tarmian and Perré (2009) reported more substantial differences in the drying kinetics and air permeability of the spruce compression wood and normal wood. This may be due to the lower initial moisture content and greater specific gravity of the reaction woods. The temperature evolution in wood during a conventional drying is density and moisture dependent. The average specific gravity was 0.46 and 0.52 for poplar normal wood and tension wood, respectively. Overall, the presence of reaction wood, especially compression wood has to be taken into account in wood drying modeling. 
144

\section{References}

Cai Y, Hayashi K, Sugimori M (2001). Three-dimensional measurement of temperature distribution in wood during Radio-Frequency/Vacuum drying. J Japan Wood Res Soc 47:389-396

Davis CP, Carrington CG, Sun ZF (2002). The influence of compression wood on the drying curves of Pinus radiata in dehumifier conditions. Drying Technol J 20(10):20052026.

Dedic AD, Mujumdar AS, Voronjec DK (2003). A three dimensional model for heat and mass transfer in convective wood drying. Drying Technol J 21(1):1-15.

Keey RB, Langrish TAG, Walker JCF (2000). Kiln-Drying of Lumber. Springer, New York.

Keey RB, Nijdam JJ (2002). Moisture movement on drying softwood boards and kiln design. Drying Technol J 20:19551974.

Li G, Plumb OA (1994). Effect of heterogeneity on wood drying, part II: experimental results. Drying Technol J 12:2003-2026.

Li XJ, Zhang BG, Li WJ (2005). Research on thermal diffusion in wood. $9^{\text {th }}$ International IUFRO Wood Drying Conference 95-100.

Mouchot N, Thiercelin F, Perre P, Zoulalian A (2006). Characterization of diffusionnal transfers of bound water and water vapor in beech and spruce. Maderas, Clencia Technol 8(3):139-147.

Pang S (1997). Relationship between a diffusion model and a transport model for softwood drying. Wood Fiber Sci 29:58-67.
Remond R, Perré P, Mougel E (2005). Using the concept of thin dry layer to explain the evolution of thickness, temperature, and moisture content during convective drying of Norway spruce boards. Drying Technol J 23:249-271.

Siau JF (1984). Transport processes in wood. Springer. Verlag, Berlin.

Tarmian A (2008). Reaction wood drying kinetics: tension wood in Fagus silvatica and compression wood in Picea abies. University of Tehran, Iran, PhD Diss. p. 110.

Tarmian A, Perré P (2009). Air permeability in longitudinal and radial directions of compression wood of Picea abies L. and tension wood of Fagus sylvatica L. Holzforschung 63:352356.

Tarmian A, Remond R, Faezipour M, Karimi K, Perré P (2009). Reaction wood drying kinetics: Tension wood in Fagus silvatica and Compression wood in Picea abies. Wood Sci Technol 43:113-130.

Wiberg P, Moren TJ (1999). Moisture flux determination in wood during drying above fiber saturation point using CTscanning and digital image processing. Holz als Roh-und Werkstoff 57(2):137-144.

Williams DH (1971). A comparison of rates of drying of "compression" and "Normal" 4 in . by 1 in. Pinus radiata. NZ For Res Inst Forest Product Report No. 303.

Zielonka P, Gierlik E (1999). Temperature distribution during conventional and microwave wood heating. Holz als Rohund Werkstoff 54:247-249. 